\title{
Throughput interventions to reduce emergency department crowding: A systematic review
}

\author{
Kiran L. Grant $\mathbb{1}^{*}$; Conrad J. Bayley, BSc ${ }^{\dagger}$; Zahra Premji, Phd ${ }^{\ddagger}$; Eddy Lang, MD, MSc ${ }^{\ddagger}$; \\ Grant Innes, MD, MSc ${ }^{\ddagger}$
}

\begin{abstract}
CLINICIAN'S CAPSULE
What is known about the topic?

Emergency department (ED) crowding is an international health system issue that increases cost and undermines patient care quality.

What did this study ask?

What throughput interventions are most effective at reducing ED length of stay and left without being seen left without being seen rates?

What did this study find?

While all intervention types reduced length of stay, triage and patient streaming interventions reported the largest reductions in length of stay and left without being seen rates.

Why does this study matter to clinicians?

Local implementation of the most effective intervention types could lessen ED crowding and contribute to increased patient and provider satisfaction.
\end{abstract}

\section{ABSTRACT}

Objective: Emergency department (ED) throughput efficiency is largely dependent on staffing and process, and many operational interventions to increase throughput have been described.

Methods: We systematically searched Medline, Embase, CINAHL, and the Cochrane Central Register of Controlled Trials to find studies describing the impact of throughput strategies on ED length of stay and left without being seen rates. Two independent reviewers screened studies, evaluated quality and risk of bias, and stratified eligible studies by intervention type. We assessed statistical heterogeneity using the chisquared statistic and the I-squared $\left(\mathrm{I}^{2}\right)$ statistic, and pooled results where appropriate. Preferred Reporting Items for Systematic Reviews and Meta-Analyses (PRISMA) guidelines were followed.

Results: Ninety-four (94) studies met inclusion criteria (Cohen's $\mathrm{k}=0.7$ ). Most were observational, five were determined to be low quality (Cohen's $k=0.6$ ), and almost all reported modest reductions in length of stay and left without being seen rates, although there was substantial variability within and between intervention types. Fast track and patient streaming interventions showed the most consistent reduction in length of stay and left without being seenrates. Shifting high-level providers to triage appears effective and generally cost neutral. Evidence for enhanced testing strategies and alternative staffing models was less compelling.

Conclusions: Introducing a fast track and optimizing processes for important case-mix groups will likely enhance throughput efficiency. Expediting diagnostic and treatment decisions by shifting physician-patient contact to the earliest possible process point (e.g., triage) is an effective cost-neutral strategy to increase flow. Focusing ED staff on operational improvement is likely to improve performance, regardless of the intervention type.

\section{RÉSUMÉ}

Contexte: L'efficience de la prise en charge au service des urgences (SU) dépend en grande partie du personnel disponible ainsi que des processus établis, et bon nombre d'interventions relatives au fonctionnement visant à accroître le débit des patients ont fait l'objet d'études.

Méthode: Une recherche systématique a été effectuée dans les bases de données Medline, Embase, CINAHL et Cochrane Central Register of Controlled Trials afin de recenser les études sur l'incidence des stratégies d'augmentation du débit sur les taux de durée de séjour et de départ sans examen médical au SU. Deux examinateurs indépendants ont procédé à une présélection des études, évalué la qualité et les risques de biais, et divisé les études admissibles selon le type d'intervention. L'hétérogénéité statistique a été évaluée à l'aide du test du chi carré et de la variable statistique I carré $\left(I^{2}\right)$, et, là où c'était indiqué, les résultats ont été mis en commun. L'étude a été réalisée conformément aux lignes directrices des Preferred Reporting Items for Systematic Reviews and Meta-Analysis (PRISMA).

Résultats: Au total, 94 études satisfaisaient aux critères de sélection (valeur de Cohen [k] : 0,7). II s'agissait pour la plupart

From the ${ }^{*}$ Faculty of Medicine, University of Toronto, Toronto, $\mathrm{ON}$; ${ }^{\dagger}$ Faculty of Medicine, University of Alberta, Edmonton, $\mathrm{AB}$; and the ${ }^{\ddagger} \mathrm{Cumming}$ School of Medicine, University of Calgary, Calgary, AB.

Correspondence to: Dr. Kiran Grant, 887 Bay St., Unit 805, Toronto, ON M5S 3K4, Canada; Email: kiran.grant@ mail.utoronto.ca. 
$d^{\prime}$ 'études d'observation, cinq étaient jugées de piètre qualité $(k: 0,6)$ et presque toutes ont fait état de faibles réductions des taux de durée de séjour et de départ sans examen médical, malgré des variations importantes entre les types d'intervention et même pour un seul type à la fois. Les interventions qui se sont révélées le plus souvent efficaces quant à la réduction des taux de durée de séjour et de départ sans examen médical étaient une ligne de conduite accélérée et la répartition des patients en groupes homogènes. La réaffectation de fournisseurs de soins avancés vers le triage semble une mesure efficace, qui n'entraîne généralement pas de coût additionnel. Par contre, les données sur de meilleures stratégies d'examens et sur d'autres modèles de dotation en personnel se sont montrées moins concluantes.
Conclusion: La mise en œuvre de lignes de conduite accélérée et de processus d'optimisation dans les groupes de maladies analogues améliorera sans doute l'efficience de la prise en charge. Le devancement de la pose du diagnostic et des prises de décision relatives au traitement vers le point le plus précoce possible du processus (par ex. le triage), au lieu de la rencontre du patient avec le médecin, est un moyen efficace, sans coût additionnel, d'accélérer le débit des patients. Inciter le personnel des SU à améliorer le fonctionnement, quel que soit le type d'intervention, augmentera sans doute le rendement.

Keywords: Crowding, emergency department, length-of-stay, throughput interventions

\section{INTRODUCTION}

Emergency department (ED) crowding is an international health system problem that is worsening. ${ }^{1}$ Crowding manifests as prolonged patient wait times and ED lengths of stay, along with increased patient mortality and morbidity. ${ }^{2-5}$

Prior work has partitioned the causes of ED crowding into three domains: input, throughput, and output. ${ }^{6}$ Input factors impact the volume and complexity of patients presenting to the ED. Output factors, including hospital bed capacity, affect the movement of patients out of the ED when they are discharged or admitted. Throughput factors, which determine the time required to assess and manage patients in the ED, are mostly dependent on ED staff and processes. ${ }^{7,8}$

Many throughput interventions have been described, including physicians or advanced providers at triage, modified staffing models, point-of-care testing, and patient streaming (e.g., fast-track, splitflow). ${ }^{9}$ Research suggests that these are variably effective, but there are no systematic reviews describing their relative impact on ED throughput. Identifying the most effective throughput interventions will become increasingly important as demand on ED services grows. It will inform health leaders which are likely to be most effective in a given setting and where to direct further study. The objective of this systematic review is to evaluate and summarize the results of studies describing ED throughput interventions.

\section{METHODS}

\section{Protocol and registration}

Study scope and inclusion/exclusion criteria were registered with PROSPERO prior to the review (registration number CRD42019125651).

\section{Search strategy}

We conducted systematic database searches in Medline (Ovid 1946 to April 26, 2020), Embase (Ovid 1974 to April 26, 2020), CINAHL (EBSCO, 1982 to April 26, 2020), and the Cochrane Central Register of Controlled Trials (Ovid, to April 26, 2020) without the use of filters or language restrictions. A sensitive four-component search was designed based on the setting (ED), factor (throughput factors), outcomes (length of stay, left without being seen rate) ${ }^{10}$ and study design (interventional studies). The ED search term was adapted from an existing search filter. ${ }^{11}$ Search strategies included free text terms and subject headings, where available. We downloaded article references and deduplicated these, using Endnote X8 software. Additional references were obtained through reference chaining of the returned articles. This study adhered to the Preferred Reporting Items for Systematic Reviews and Meta-Analyses (PRISMA) guidelines. ${ }^{12}$

\section{Eligibility criteria}

Original research articles describing throughput interventions to reduce ED crowding were considered for 
inclusion. Studies had to have a concurrent or historical comparison group and report length of stay or left without being seen rates as outcomes. Studies were excluded if they were published only as abstracts, published in a language other than English, or lacked a comparator group.

\section{Screening and data extraction}

After eliminating duplicates, two reviewers (KG and $\mathrm{CB}$ ) independently screened all titles and abstracts. Disagreements were resolved by consensus or, if necessary, by a third independent reviewer (EL). Inter-rater reliability was assessed using Cohen's kappa statistic. All remaining studies underwent a full-text review. Relevant data were extracted using a pre-prepared data sheet that included a title, authors, publication date, design, outcome measures, and main results.

\section{Risk of bias}

We used the Cochrane risk of bias tool (version 2) to assess randomized controlled trials and the National Heart, Lung, and Blood Institute (NHLBI) quality assessment tools for other study designs. ${ }^{13,14}$ Two independent reviewers (KG and $\mathrm{CB}$ ) assessed risk of bias for all papers. Inter-rater reliability was calculated using Cohen's kappa statistic. Disagreements were resolved by consensus or, if necessary, by a third independent reviewer.

\section{Data analysis}

Included studies were summarized in tabular form, describing title, authors, study design, intervention, and primary outcomes. Study methods were reviewed to determine whether the interventions were implemented using existing ED resources (resource neutral) or whether they required additional resources.

Our intention was to perform meta-analyses and derive pooled estimates from studies of similar design and intervention type. We assessed statistical heterogeneity using the chi-squared statistic and the I-squared $\left(\mathrm{I}^{2}\right)$ statistic, with $\mathrm{I}^{2}$ values of $25 \%, 50 \%$, and $75 \%$ representing low, moderate, and high degrees of heterogeneity, respectively. These analyses revealed that only two studies were sufficiently similar to enable pooling. We combined and weighted these studies using the Mantel-Haenszel variance method and random effects models, and determined weighted mean differences (WMD) with a $95 \%$ confidence interval (CI) for length of stay. The remaining studies were not pooled due to high levels of methodological or statistical heterogeneity. Instead, effect sizes with corresponding 95\% CIs were presented for each. Means and standard deviations (SDs) were calculated for each study outcome. For those that did not report SDs, we determined SD using reported CIs, $p$-values, interquartile ranges, or imputed values from other studies reporting similar outcomes in similar populations. Changes in left without being seen rates were reported as risk ratios (RR), representing a proportional increase or decrease.

\section{RESULTS}

\section{Literature search}

Of 3,284 papers identified, 211 met inclusion criteria after title/abstract screening. There were 163 disagreements between reviewers, all resolved by consensus (Cohen's kappa $=0.7)$. Of 211 papers that underwent a full-text review, 59 were excluded because they were not focused on throughput interventions, incorporated non-throughput interventions, or did not report key outcomes (length of stay or left without being seen). An additional 53 papers were excluded because they were published only in abstract form and lacked an adequate description of methods, results, or analysis. This left 97 papers appropriate for qualitative synthesis and two for quantitative synthesis.

\section{Description of studies}

Of the 99 studies, 52 were American, 17 were Australian, 15 were European, 8 were Canadian, 6 were Asian, and 1 was Jamaican. The studies were divided into seven categories based on intervention type. Triage interventions included triage process modifications but excluded strategies that directed patients away from the ED, as these modify input rather than throughput. Testing strategies included interventions to improve laboratory turnaround time or to introduce point-of-care testing. Alternative staffing models introduced scribes, nurses, physicians, paramedics, or nurse practitioners with innovative roles. Specific patient populations studied new approaches to specific populations (e.g., mental health assessment teams). Streaming interventions involved new care areas (e.g., fast-track) or separate care pathways 
for specific patient cohorts. Integrated approaches incorporated multiple-linked interventions. Interventions that did not fit the previous categories were classified as other.

\section{Risk of bias}

Of the 99 studies included, 91 were assessed using the NHLBI study quality assessment tools. Nineteen were rated good, 67 fair, and 5 poor. Eight studies were assessed using the Cochrane risk of bias tool (Version 2). Three had a low risk of bias, five had some concerns, and none had a high risk of bias. There were 15 interobserver disagreements (Cohen's $\mathrm{k}=0.6$ ), all resolved by consensus.

\section{Pooled analyses}

We pooled data from two studies on physician triage based on low statistical heterogeneity $(<25 \%)$. One placed a supernumerary physician at triage, while the other moved a physician from ED bedside care to the triage area. Both demonstrated significant length of stay reductions compared to nurse-led triage (WMD: 11.7 minutes; $95 \% \mathrm{CI}=6.8-16.6){ }^{15,16}$

\section{Non-pooled analyses}

Due to clinical or statistical heterogeneity, the data from 92 remaining studies were not pooled. Outcomes for these studies are presented within the relevant intervention category.

\section{Triage interventions}

Six physicians in triage interventions (Table 1) reported length of stay changes between -82 minutes and +18 minutes $(-20.7 \%$ to $+7.2 \%) .{ }^{17-22}$ Five nurse practitioners or physician assistant-led triage interventions resulted in length of stay changes of -106 minutes to +19 minutes $(-22 \%$ to $+7.3 \%){ }^{23-27}$ Five team triage interventions reported length of stay reductions of 4 to 34 minutes $(8 \%-16 \%){ }^{22,28-30}$ Two studies of telemedicine triage reported a 0.3 - and 8-minute increases in length of stay, respectively. ${ }^{31,32}$

Six physician at triage interventions also yielded significant left without being seen improvement $(R R=0.3$ to 0.8 ), whereas three others reported non-significant results. ${ }^{17-22}$ One study of physician assistant-led triage reported a significant improvement $(R R=0.2)$, whereas one study of nurse practitioner triage and another using an undefined "triage liaison provider" reported non-significant results. ${ }^{24,25,27}$ Four team triage interventions generated left without being seen changes ranging from a meaningful improvement $(\mathrm{RR}=0.6)$ to substantial deterioration $(\mathrm{RR}=1.7) .^{22,28-30}$

\section{Specific patient populations}

Five studies focused on the care of specific patient populations and reported length of stay reductions within these target populations, as opposed to the ED overall (see Table 2). Three reported 60- to 227-minute length of stay reductions after adding physiotherapists as primary providers for patients with musculoskeletal injuries. ${ }^{33-35}$ Another described a 30-minute (16\%) length of stay reduction after stationing a neurologist in the ED. ${ }^{36}$ The introduction of weekday psychiatrist rounds on ED mental health patients did not significantly improve length of stay nor did an Rh testing protocol for pregnant women. ${ }^{37,38}$ Only one study measured left without being seen rates, reporting a significant improvement $(\mathrm{RR}=0.6)$ associated with a dedicated neurologist in the ED.

\section{Testing strategies}

Twelve point-of-care testing intervention studies reported length of stay changes ranging from -114 minutes to +8 minutes $(-26.8 \%$ to $+3.8 \%)$, although three of these were non-significant findings (Table 3). ${ }^{39-50}$ Four studies on point-of-care testing or lab-ordering at triage reported length of stay reductions ranging from 22 to 174 minutes, but only one of these, at 29 minutes (16\%), was significant. ${ }^{51-54}$ One study where triage nurses ordered X-rays using the Ottawa ankle rules reported a non-significant length of stay reduction of 28 minutes $(6.4 \%) .{ }^{55,56}$ Length of stay changes were limited to the population of patients who underwent lab testing, and none of these studies reported effects on left without being seen.

\section{Alternative ED staffing models}

Two studies reported that ED scribes were associated with significant length of stay reductions of 16-19 minutes $(5.3 \%-9.9 \%),{ }^{57}$ but three others found nonsignificant increases of $1-10$ minutes (Table 3). ${ }^{5-62}$ 


\begin{tabular}{|c|c|c|c|c|c|}
\hline Study* & Country & Design & Intervention: Triage & $\begin{array}{l}\text { Change LOS } \\
\text { (Mins) }\end{array}$ & $\mathrm{ROB}$ \\
\hline $15 \sim$ & USA & Pre-post & Physician in triage (PIT) initiates diagnostic evaluation. & -11 & Fair \\
\hline $16 \sim$ & USA & Pre-post & PIT screens patients for acuity and initiates diagnostic workup. & -13 & Fair \\
\hline $17 \sim$ & USA & Pre-post & PIT initiates diagnostic studies and performs basic interventions. & -82 & Fair \\
\hline $18 \sim$ & Canada & RCT^ & PIT initiates early evaluation, investigation, and treatment. & -36 & Low \\
\hline $19 \sim$ & USA & Pre-post & Physician, nurse, and resident triage team. & -27 & Fair \\
\hline $20 \sim$ & USA & Pre-post & PIT performs clinical assessment and orders initial testing. & -12 & Good \\
\hline $21 \sim$ & USA & Pre-post & $\begin{array}{l}\text { During surges, PIT initiates care for high-acuity patients and discharges } \\
\text { low acuity patients. If no PIT is available, RN initiates protocol-guided } \\
\text { tests. }\end{array}$ & -2 & Fair \\
\hline $22 \sim$ & Sweden & Pre-post & Traditional nurse-led triage v. MD in triage v. interprofessional triage. & -106 & Good \\
\hline $23 \sim$ & USA & Pre-post & $\begin{array}{l}\text { Advanced nursing interventions: RN-ordered lab or X-ray studies, and } \\
\text { administered medication at triage for ESI-3 patients with abdominal pain. }\end{array}$ & -41 & Fair \\
\hline $24 \sim$ & USA & Pre-post & PA assists with triage (history, physical, investigations). & 19 & Good \\
\hline $25 \sim$ & USA & Pre-post & NP moved from fast track to triage; initiates history, physical, and testing. & -52 & Fair \\
\hline $26 \sim$ & USA & Cohort & $\begin{array}{l}\text { Nurses initiated triage standing orders for patients with chest pain, } \\
\text { dyspnea, abdominal pain, or genitourinary complaints if no beds were } \\
\text { available. }\end{array}$ & -17 & Good \\
\hline $27 \sim$ & USA & Pre-post & NP in triage who takes a brief history and assigns an acuity score. & -34 & Poor \\
\hline $28 \sim$ & Sweden & Pre-post & Physician-led triage team (senior \& junior physician, RN, assistant nurse). & -29 & Fair \\
\hline $29 \sim$ & USA & Pre-post & $\begin{array}{l}\text { Supplemented triage and rapid treatment (START): triage team that } \\
\text { initiated testing and accelerated disposition for selected patients. }\end{array}$ & -21 & Good \\
\hline $30 \sim$ & USA & Cluster RCT & Physician-led triage team (physician, nurse, nurse's assistant). & -4 & Fair \\
\hline $31 \sim$ & USA & Pre-post & $\begin{array}{l}\text { Tele-intake providers performed a triage history and physical, documented } \\
\text { findings, and initiated orders from 1100-1900 hours, } 6 \text { days per week. }\end{array}$ & 0.3 & Fair \\
\hline $32 \sim$ & USA & Pre-post & Standard nursing triage $+/-$ telemedical physician triage. & 8. & Poor \\
\hline Study* & Country & Design & Intervention: specific patient population & $\begin{array}{l}\text { Change } \\
\text { LOS (mins) }\end{array}$ & RoB \\
\hline $33 \$$ & Australia & Pre-post & Physiotherapist first assessment and care of MSK injuries. & -108 & Fair \\
\hline $34 \$$ & Australia & $\begin{array}{l}\text { Prospective } \\
\text { observational }\end{array}$ & $\begin{array}{l}\text { Primary care physicians manage ED patients with musculoskeletal } \\
\text { injuries, fractures, and minor wounds. }\end{array}$ & -81 & Fair \\
\hline $35 \$$ & Australia & Pre-post & Physiotherapist first assessment and care of MSK injuries. & -60 & Fair \\
\hline $36 \sim$ & Nether-lands & Cross-section & Dedicated neurologist in the ED outside office hours instead of home call. & -30 & Fair \\
\hline $37 \$$ & USA & Pre-post & Weekday rounds by attending psychiatrists on ED mental health patients. & -2 & Fair \\
\hline $38 \sim$ & Australia & Pre-post & Expanded RN role: nurse-initiated X-rays of isolated lower limb injury. & -60 & Fair \\
\hline
\end{tabular}

Hess et al. reported that scribes increased left without being seen rates $(\mathrm{RR}=1.5)$, whereas Murphy et al. reported that the addition of a nurse flow coordinator reduced length of stay by 87 minutes $(32 \%)$ and decreased left without being seen rates $(\mathrm{RR}=0.7) .{ }^{60,63}$ Three studies added nurse practitioners or additional physician shifts, and reported length of stay changes ranging from +2 to -76 minutes. ${ }^{64-66}$

\section{Streaming}

Nine studies looked at the impact of split-flow processes that created patient streams based on acuity, presenting complaint, or ability to ambulate, and reported significant overall ED length of stay reductions from 9-60 minutes (4.0\%-41.6\%) (Table 2). ${ }^{67-75}$ Fast-track interventions are similar to split flow but apply specifically to mid-/ 


\begin{tabular}{|c|c|c|c|c|c|}
\hline Study* & Country & Design & Intervention: Patient streaming & $\begin{array}{l}\text { Change LOS } \\
\text { (Mins) }\end{array}$ & $\mathrm{ROB}$ \\
\hline $67 \$$ & USA & Chart review & $\begin{array}{l}\text { Split flow model separates high and low-variability ESI } 3 \text { patients into two } \\
\text { tracks }\end{array}$ & -9 & Fair \\
\hline $68 \$$ & USA & Pre-post & Midlevel providers (NP or PA) assigned to the RME area during volume surges. & -58 & Fair \\
\hline $69 \sim$ & Australia & Pre-post & $\begin{array}{l}\text { Streaming: high-acuity patients prioritized by triage level; low-acuity by arrival } \\
\text { time. }\end{array}$ & -48 & Poor \\
\hline $70 \sim$ & UK & Pre-post & $\begin{array}{l}\text { Reassigned existing staff to rapid medical evaluation unit for low-acuity } \\
\text { patients. }\end{array}$ & -36 & Fair \\
\hline $71 \$$ & USA & Pre-post & Rapid entry and accelerated care at triage (REACT). & -31 & Fair \\
\hline $72 \sim$ & Australia & Pre-post & $\begin{array}{l}\text { SAFE-T (senior streaming assessment and further evaluation after triage) } \\
\text { zone. }\end{array}$ & -30 & Fair \\
\hline $73 \sim$ & USA & Pre-post & Vertical split flow: assign low-acuity patients virtual rather than actual ED beds. & -17 & Fair \\
\hline $74 \sim$ & USA & Pre-post & $\begin{array}{l}\text { Bedside registration: patients triaged to bed and registered after MD } \\
\text { evaluation. }\end{array}$ & -15 & Fair \\
\hline $75 \$$ & Australia & Pre-post & $\begin{array}{l}\text { Complex ambulatory patients streamed to existing high-acuity or fast track } \\
\text { zones. }\end{array}$ & -60 & Fair \\
\hline $76 \sim$ & USA & Pre-post & Flow-capacity expansion replaced stretchers with multiple chairs. & -114 & Fair \\
\hline $77 \sim$ & Nether-lands & Pre-post & Nurse and PA-staffed fast track for low-acuity patients needing surgery. & -12 & Good \\
\hline $78 \$$ & Australia & Pre-post & Fast track for low-acuity ATS 3/4/5 patients, staffed by an MD-RN team. & -20 & Fair \\
\hline $79 \sim$ & USA & Pre-post & Minor care resources repurposed to fund fast track staffed by one or two NPs. & -19 & Fair \\
\hline $80 \sim$ & Australia & Case-control & Fast track (treatment rooms + chairs) staffed by ED nurse and registrar or NP. & -16 & Good \\
\hline $81 \sim$ & USA & Pre-post & Reorganization of patient flow through existing rooms. No new staff or space. & -15 & Good \\
\hline $82 \$$ & USA & Pre-post & PA and ED technician manage low-acuity patients in a dedicated area. & -74 & Fair \\
\hline $83 \$$ & USA & Pre-post & Fast track run by an interdisciplinary team with NPs for low-acuity patients. & -54 & Poor \\
\hline $84 \$$ & Australia & Pre-post & $\begin{array}{l}\text { Lean-based fast track for low-acuity patients; staffed by two nurses and } \\
\text { physician. }\end{array}$ & -46 & Fair \\
\hline $85 \sim$ & Pakistan & Cross-section & Dedicated low-acuity fast track area run by mid-level providers. & -38 & Fair \\
\hline $86 \sim$ & USA & Pre-post & Midtrack area dedicated to ESI 3 patients; staffed by a physician and two RNs. & -36 & Fair \\
\hline 87 & USA & Pre-post & NP-managed fast track area for low-complexity patients. & -34 & Fair \\
\hline $88 \sim$ & Spain & Pre-post & Resident-managed fast track for low-acuity patients. & -27 & Fair \\
\hline $89 \sim$ & Turkey & Clinical trial & Fast-track team for defined low-acuity patients. & -28 & Good \\
\hline $90 \sim$ & USA & Pre-post & $\begin{array}{l}\text { Pediatric fast track for acute patients with fever, vomiting, diarrhea, or poor } \\
\text { intake. }\end{array}$ & -27 & Fair \\
\hline $91 \sim$ & UK & Pre-post & Fast-track for patients with minor injuries or more benign conditions. & -29 & Fair \\
\hline $92^{*} \sim$ & USA & Pre-post & $\begin{array}{l}\text { New pediatric triage guidelines to direct most appropriate patients to fast } \\
\text { track. }\end{array}$ & $\begin{array}{l}\text { Did not report } \\
\qquad \text { LOS }\end{array}$ & Fair \\
\hline \multicolumn{6}{|c|}{$\begin{array}{l}\text { Notes: Studies are identified by reference number (see Appendix 1). } \\
\text { ARCTs were assessed using the Cochrane RoB-2 tool (low/some concerns/high risk of bias); "\$" indicates that the intervention required additional resources; *Study } 92 \text { did not report length of } \\
\text { stay, only left without being seen rate; " } \sim \text { "indicates cost-neutral intervention; } \wedge \text { mixed methods study. } \\
\text { CPOE = computerized provider order entry; EDIS = ED information system; LOS = length of stay; MAU = medical assessment; } M S=\text { musculoskeletal; } P I T=\text { physician in triage; RME = rapid } \\
\text { medical evaluation unit; RoB = risk of bias. }\end{array}$} \\
\hline
\end{tabular}

low-acuity ambulatory patients who are likely to be discharged quickly after assessment. Fourteen of 15 fast-track studies showed statistically significant overall ED length of stay reductions ranging from 12-114 minutes $(10 \%-47.5 \%) .{ }^{76-91}$ One split-flow study assessed left without being seen rates, finding a $43 \%$ reduction $(\mathrm{RR}=0.6) .{ }^{71}$ Of seven fast-track studies that assessed left without being seen rates, six reported significant reductions $(\mathrm{RR}=0.5-0.8){ }^{79,83,84,86-88,92}$

\section{Integrated approaches}

Several investigators implemented multiple interventions simultaneously (Table 4). Twelve of 15 reported significant overall ED length of stay reductions ranging from 2 to 114 minutes $(1 \%-41 \%) .{ }^{93-106}$ Five studies also documented left without being seen rates, with four reporting significant improvements $(\mathrm{RR}=0.02-0.8)$. The most substantial improvements 


\begin{tabular}{|c|c|c|c|c|c|}
\hline Study* & Country & Design & Intervention: Testing strategies & $\begin{array}{l}\text { Change LOS } \\
\text { (Mins) }\end{array}$ & ROB \\
\hline $39 \$$ & USA & Pre-post & $\begin{array}{l}\text { Bedside nurses perform POCT Tn-I on admitted chest pain } \\
\text { patients. }\end{array}$ & -114 & Fair \\
\hline $40 \$$ & Canada & $\mathrm{RCT} \wedge$ & Comprehensive РОСТ: hematology, electrolytes, troponin. & -54 & Low \\
\hline $41 \$$ & USA & Pre-post & New ED POC satellite lab with nurse and lab tech (Mon-Fri). & -42 & Fair \\
\hline $42 \$$ & Korea & $\mathrm{RCT} \wedge$ & Comprehensive POCT and urinalysis done by EMT. & -22 & $\begin{array}{l}\text { Some } \\
\text { concerns }\end{array}$ \\
\hline $43 \$$ & UK & $\mathrm{RCT} \wedge$ & $\begin{array}{l}\text { ED blood draw. POC analysis done in lab and using bedside } \\
\text { analyzer. }\end{array}$ & -5 & Low \\
\hline $44 \$$ & USA & Pre-post & ED-based I-STAT cardiac troponin and Chem8. & -2 & Good \\
\hline $45 \$$ & USA & Pre-post & ED POCT ( $\mathrm{Na}, \mathrm{K}, \mathrm{Cl}$, glucose, and BUN) by non-lab-technicians. & 8 & Good \\
\hline $46 \$$ & USA & $\mathrm{RCT} \wedge$ & Pediatric ED: I-Stat Analyzer (expanded electrolytes, blood gas). & 3 & $\begin{array}{l}\text { Some } \\
\text { concerns }\end{array}$ \\
\hline $47 \$$ & USA & Pre-post & Comprehensive ED POCT for all 15 critical care beds in an ED. & -3 & Good \\
\hline $48 \$$ & USA & Pre-post & $\begin{array}{l}\text { Comprehensive ED-dedicated stat lab within the central } \\
\text { laboratory. }\end{array}$ & -21 & Fair \\
\hline $49 \$$ & Finland & $\begin{array}{l}\text { Prospective, } \\
\text { observational }\end{array}$ & $\begin{array}{l}\text { Comprehensive POCT and early assessment team intervention } \\
\text { (resident plus nurse). }\end{array}$ & -29 & Fair \\
\hline $50 \$$ & Australia & Pre-post & Comprehensive ED POCT in 26 rural and remote EDs. & -7 & Fair \\
\hline $51 \$$ & USA & Case-control & Comprehensive triage-based POCT performed by RN. & -174 & Good \\
\hline $52 \$$ & USA & Pre-post & POC D-dimer test added to existing ED satellite laboratory. & -80 & Fair \\
\hline $53 \sim$ & Australia & Observational & Color-coded sample priority indicators for lab to improve TAT. & -29 & Fair \\
\hline $54 \$$ & Korea & Pre-post & Triage-ordered CBC \& chemistry testing: sampling area near triage. & -22 & Fair \\
\hline $55 \$$ & Canada & $\mathrm{RCT} \wedge$ & Triage nurse ordering $X$-rays based on the Ottawa ankle rules. & -28 & $\begin{array}{l}\text { Some } \\
\text { concerns }\end{array}$ \\
\hline $56 \sim$ & USA & $\begin{array}{l}\text { Retrospective } \\
\text { observational }\end{array}$ & $\begin{array}{l}\text { Reorganizing timing of phlebotomy and troponin orders to improve } \\
\text { turnaround time (TAT) for troponin testing in central lab. }\end{array}$ & -43 & Good \\
\hline Study* & Country & Design & Intervention: Alternative staffing models & $\begin{array}{l}\text { Change LOS } \\
\text { (Mins) }\end{array}$ & $\mathrm{ROB}$ \\
\hline $57 \$$ & UK & $\mathrm{RCT} \wedge$ & Scribes providing one-to-one physician support. & -19 & $\begin{array}{l}\text { Some } \\
\text { concerns }\end{array}$ \\
\hline $58 \$$ & USA & Pre-post & Scribes transcribe and complete clerical tasks. & -16 & Fair \\
\hline $59 \$$ & Australia & Prospective cohort & Scribes providing one-to-one physician support. & 1 & Fair \\
\hline $60 \$$ & USA & Pre-post & Scribes to assist workup initiation. & 9 & Fair \\
\hline $61 \$$ & USA & Prospective cohort & Scribes providing one-to-one physician support. & 10 & Fair \\
\hline $62 \sim$ & USA & Prospective cohort & Scribes providing one-to-one physician support. & -5 & Fair \\
\hline $63 \$$ & USA & Pre-post & New ED flow coordinator focused on patient movement. & -87 & Poor \\
\hline $64 \$$ & Australia & Case review & New ED NP candidates focused on lower-acuity patients. & -76 & Fair \\
\hline $65 \$$ & Canada & Pre-post & New broad-scope NP on weekdays for low-acuity patients. & 2 & Fair \\
\hline $66 \$$ & Switzer-land & Pre-post & One additional on-duty physician per shift. & -35 & Fair \\
\hline
\end{tabular}

were seen with tailored ED process redesign, a combination of streaming, team-based assessment and early senior consultation. ${ }^{95-97,106}$

\section{Other throughput interventions}

Eight interventions did not fit well within a defined category (Table 4). ${ }^{107-114}$ Five of these led to length 


\begin{tabular}{|c|c|c|c|c|c|}
\hline Study & Country & Design & Intervention: Integrated approaches & $\begin{array}{l}\text { Change LOS } \\
\text { (Mins) }\end{array}$ & $\mathrm{ROB}$ \\
\hline $93 \$$ & USA & Pre-post & Rapid triage, replace gurneys with recliners, divide ED into high-/low-acuity areas. & -114 & Fair \\
\hline $94 \sim$ & Spain & Pre-post & $\begin{array}{l}\text { Team-based, 2-hour evaluation, and referral stream and early senior } \\
\text { consultation. }\end{array}$ & -87 & Fair \\
\hline $95 \sim$ & Australia & Pre-post & $\begin{array}{l}\text { Reorganization: value stream mapping, waste reduction; standardized } \\
\text { processes. }\end{array}$ & -60 & Fair \\
\hline $96 \$$ & UK & Cohort* & Rapid patient assessment by consultants and POC testing. & -53 & Fair \\
\hline $97 \sim$ & Canada & Pre-post & $\begin{array}{l}\text { Triage to internal waiting area, registration efficiencies, flexible nursing ratios, } \\
\text { and demand-based physician scheduling. }\end{array}$ & -38 & Fair \\
\hline $98 \$$ & Jamaica & Pre-post & $\begin{array}{l}\text { "Be quick": quick triage, bedside registration, "bed-ahead" strategy, EMR } \\
\text { with tracking board, and four-bed fast track. }\end{array}$ & -36 & Good \\
\hline $99 \sim$ & USA & Cross-section & Team triage (physician and two nurses) for low-acuity fast track patients. & -30 & Fair \\
\hline $100 \sim$ & USA & Pre-post & PIT and split flow: low- and high-acuity patients to rapid v. acute care areas. & -29 & Poor \\
\hline $101 \$$ & Switzerland & Pre-post & Medical team evaluation (MTE): team triage, quick registration, and EMR. & -15 & Good \\
\hline $102 \$$ & USA & Pre-post & Scribes coupled with computerized physician order entry. & -14 & Fair \\
\hline $103 \$$ & Netherlands & Cross-section & $\begin{array}{l}\text { Adding NP, adding five medical specialists during peak hours, lean program to } \\
\text { improve radiology turnaround times, and extending the admission offices' } \\
\text { hours. }\end{array}$ & -13 & Fair \\
\hline $104 \sim$ & Australia & Pre-post & PIT and MAU to expedite specialist care while patients wait for consultants. & -11 & Fair \\
\hline $105 \$$ & USA & Pre-post & Flexible Care Area for low- and mid-acuity patients: keeps patients "vertical." & $\begin{array}{l}-3 \text { (CTAS } \\
5 \text { pts) } \\
-2 \text { (CTAS } 2 \text { pts) }\end{array}$ & Fair \\
\hline $106 \sim$ & USA & Pre-post & Lean methods applied to create more efficient front-end approaches. & 18 & Fair \\
\hline Study & Country & Design & Intervention: Other & $\begin{array}{l}\text { Change LOS } \\
\text { (Mins) }\end{array}$ & $\mathrm{ROB}$ \\
\hline $107 \$$ & USA & Pre-post & EDIS with patient tracking; CPOE; direct access to patient historical data. & -116 & Fair \\
\hline $108 \sim$ & USA & Pre-post & Triage team initiates testing and rapid disposition for selected patients. & -56 & Fair \\
\hline $109 \sim$ & USA & Pre-post & New MD signup: patients assigned to physicians automatically by algorithm. & -24 & Good \\
\hline $110 \sim$ & Taiwan & Pre-post & $\begin{array}{l}\text { Peer pressure: ED physician discharge rates publicized to group by monthly } \\
\text { email. }\end{array}$ & -18 & Fair \\
\hline $111 \sim$ & Korea & Pre-post & $\begin{array}{l}\text { Computerized short messaging service informs care providers of patient } \\
\text { delays. }\end{array}$ & -14 & Fair \\
\hline $112 \$$ & Canada & $\begin{array}{l}\text { Interrupted time } \\
\text { series }\end{array}$ & $\begin{array}{l}\text { Physician compensation switched from flat rate contract to fee-for service } \\
\text { payment that rewards volume. }\end{array}$ & -5 & Good \\
\hline $113 \$$ & USA & Pre-post & Replaced paper with custom provider electronic documentation system (eDoc). & 8 & Good \\
\hline $114 \$$ & Canada & $\begin{array}{l}\text { Retrospective } \\
\text { cohort }\end{array}$ & $\begin{array}{l}\text { CPOE with alerts for allergies, potential medication reactions, and } \\
\text { evidence-based clinical decision support. }\end{array}$ & 10 & Good \\
\hline \multicolumn{6}{|c|}{$\begin{array}{l}\text { Notes: Studies are identified by reference number (see Appendix 1). } \\
\text { ARCTs were assessed using the Cochrane RoB- } 2 \text { tool (low/some concerns/high risk of bias); " } \$ \text { " indicates that the intervention required additional resources; " } \sim \text { " indicates cost-neutral } \\
\text { intervention; and ^mixed methods study. } \\
C P O E=\text { computerized provider order entry; EDIS = ED information system; LOS = length of stay; } M A U=\text { medical assessment; } M S=\text { musculoskeletal; PIT = physician in triage; pts = patients; } \\
\text { RME = rapid medical evaluation unit; ROB = risk of bias. }\end{array}$} \\
\hline
\end{tabular}

of stay reductions, including an ED patient tracking system, a dedicated early assessment clinical team, and computerized order entry. Physician transition from contract to fee-for-service payment did not significantly reduce length of stay, nor did computerized provider order entry or electronic documentation systems. Only two studies in this category reported left without being seen outcomes. Automatically assigning patients to physicians by algorithm led to a $7 \%$ increase $(\mathrm{RR}=1.1)$, whereas computerized order entry led to a $51 \%$ decrease $(\mathrm{RR}=0.5){ }^{109,114}$ 


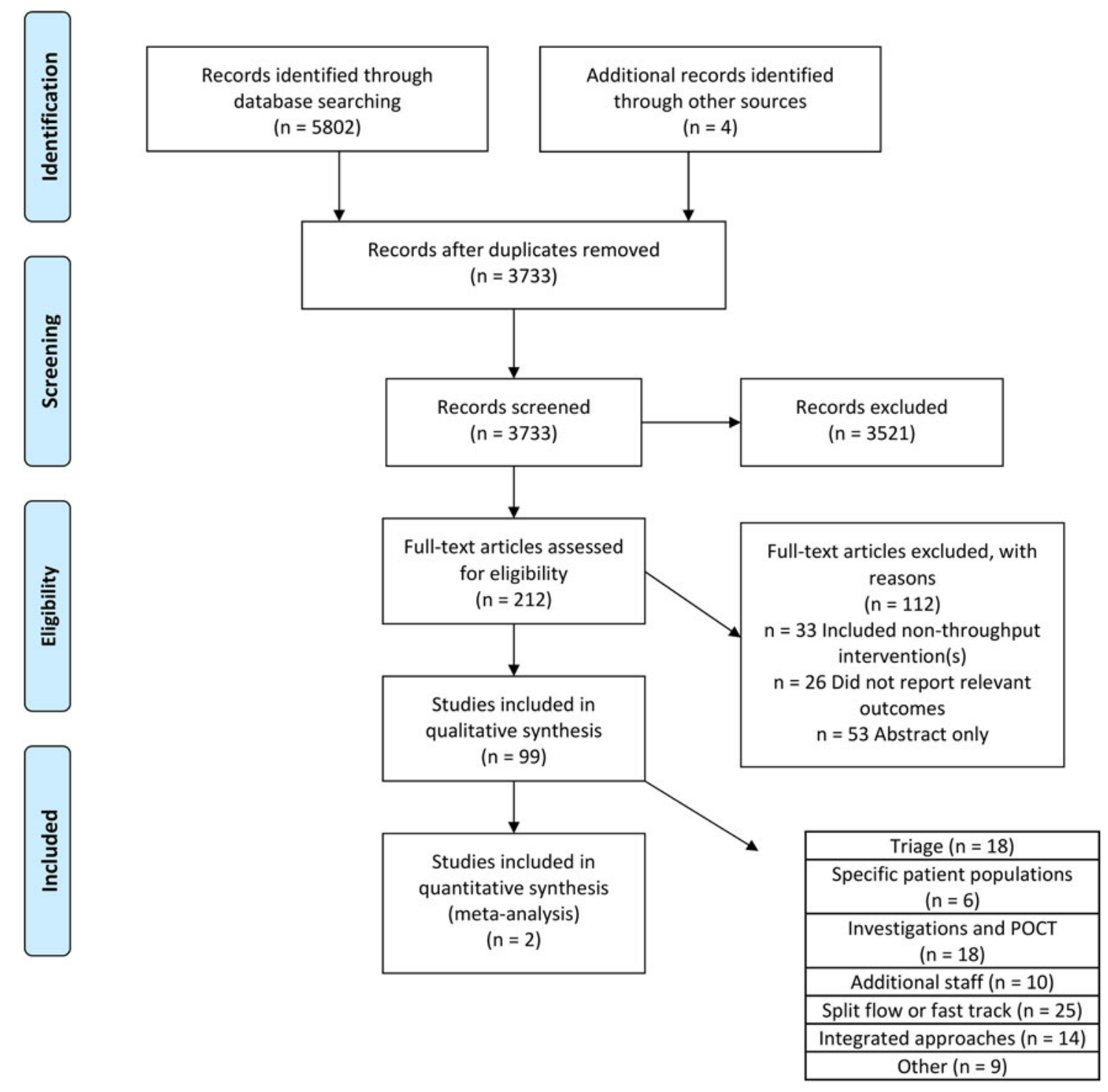

Figure 1. PRISMA flow diagram.

\section{DISCUSSION}

\section{Interpretation}

This systematic review summarizes evidence describing the effectiveness of throughput interventions. Overall, 80 of 94 studies reported modest improvements, almost irrespective of approach. A consistent modest improvement from diverse interventions, in part, could reflect publication bias. It also suggests the possibility that, in many cases, observed benefits may relate more to enhanced focus on operational improvement (Hawthorne effect) than to specific effects of the intervention.

\section{Prior studies}

Previous systematic reviews have focused on interventions in triage, patient streaming, or nurse practitioners or scribes in the ED. ${ }^{115-120}$ Our findings are congruent with the findings of these reviews.

\section{Strengths and limitations}

We found a paucity of high-quality evidence describing ED throughput interventions. Most studies used observational pre-post designs, which are vulnerable to bias and fail to account for confounders. High levels of heterogeneity precluded data pooling in all but two cases, 
making robust comparisons within and between intervention categories difficult. Only a handful of papers studied concurrent controls, and few assessed sustainability of the observed improvements. Further, while all of the studies assessed the impact of throughput interventions on length of stay or left without being seen, these outcomes are affected by other factors that were not described or incorporated in analyses. None of the studies provided meaningful cost-effectiveness analyses, and, in cases where new resources were committed or existing staff redeployed, the opportunity costs (potential benefits of alternative approaches) were not discussed. Finally, given the large number of EDs continually involved in operational improvement, the relatively small number of studies that we identified suggests that the overall positive outcomes seen in this data set, in part, could reflect publication bias. ${ }^{121}$

\section{Clinical implications}

The optimal intervention for a given ED and hospital system will depend on a number of factors, including the available staff and their expertise, physical space and funding, and the ED's case mix. ED leaders interested in improving throughput should evaluate the feasibility of implementing a given intervention type within their ED, and then look to the studies that reported the greatest reductions in length of stay within that intervention type for guidance. A quality improvement approach using Plan-Do-Study-Act cycles could enable an ED to relatively quickly and cost-effectively trial an intervention, and iterate upon it as needed.

Streaming and fast track were the most consistently effective intervention types, showing length of stay reductions in every case, ranging from 9 to 114 minutes. Introducing a fast track and optimizing care processes for important case-mix groups seem an obvious starting point for EDs with throughput challenges, though they do require expanding or reworking the ED space.

Earlier physician or provider assessment at triage is an effective strategy that makes use of existing resources and modestly improves ED length of stay. Several studies evaluated scribes, nurse practitioners, or other providers in non-triage roles. These changes involve additional staffing costs, and, while some appeared potentially promising, supporting evidence was of insufficient quality or quantity to warrant any strong recommendations. New diagnostic testing and point-of-care testing strategies were also associated with incremental cost, and reductions in length of stay were limited to relevant patient subsets (e.g., those requiring troponin testing), making these interventions best suited to EDs where a large number of patients have similar presentations.

If there is a unifying theme in the "integrated approaches" category, it would be optimizing process effciency. While some interventions showed large overall length of stay reductions, they were generally more complex and costly. We advise readers to review these approaches and to prioritize other intervention types.

\section{Research implications}

Future research should apply more robust study designs, including randomized trials, stepped wedge implementations and interrupted time series analyses, and consider reporting a broader range of outcomes, including quality measures of patient satisfaction, and staff satisfaction.

\section{CONCLUSION}

Introducing a fast track and optimizing processes for important case-mix groups are likely to enhance throughput. Expediting diagnostic and treatment decisions by shifting physician-patient contact to the earliest possible process point (e.g., triage) is an effective costneutral strategy to improve flow. Evidence is insufficient to warrant recommendations for or against alternative staffing models. Focusing ED staff on operational improvement is likely to improve performance, regardless of the intervention type.

Supplementary material: The supplementary material for this article can be found at https://doi.org/10.1017/cem.2020.426.

Competing interests: None declared.

\section{REFERENCES}

References $17-114$ are listed in supplementary material.

1. Schull MJ, Slaughter PM, Redelmeier DA. Urban emergency department overcrowding: defining the problem and eliminating misconceptions. CFEM 2002;4(2):76-83.

2. Derlet RW, Richards JR. Overcrowding in the nation's emergency departments: complex causes and disturbing effects. Ann Emerg Med 2000;35(1):63-8. 
3. Fatovich DM, Nagree Y, Sprivulis P. Access block causes emergency department overcrowding and ambulance diversion in Perth, Western Australia. Emerg Med 7 2005;22(5):351-4.

4. Olshaker JS. Managing emergency department overcrowding. Emerg Med Clin North Am 2009;27(4):593-603, viii.

5. Shih FY, Ma MH, Chen SC, et al. ED overcrowding in Taiwan: facts and strategies. Am $\mathcal{F}$ Emerg Med 1999; 17(2):198-202.

6. Asplin BR, Magid DJ, Rhodes KV, et al. A conceptual model of emergency department crowding. Ann Emerg Med 2003;42(2):173-80.

7. Handel DA, Hilton JA, Ward MJ, et al. Emergency department throughput, crowding, and financial outcomes for hospitals. Acad Emerg Med 2010;17(8):840-7.

8. Anderson W, Lukas B, Jones S, Sharma J, Bastani A. How much to buy down your throughput? Acad Emerg Med 2016;23(Suppl 1):S206.

9. Chan L, Reilly KM, Salluzzo RF. Variables that affect patient throughput times in an academic emergency department; 2016. Available at: https://doiorg/101177/0885713X9701200 403 (accessed Feb 23, 2020).

10. Improved flow aids patient safety: cut wait times, LWBS, boost compliance. ED Manag 2011;23(1):10-1.

11. Rogers BB, Shankar P, Jerris RC, et al. Impact of a rapid respiratory panel test on patient outcomes. Arch Patbol Lab Med 2015;139(5):636-41.

12. Tricco AC, Lillie E, Zarin W, et al. PRISMA extension for scoping reviews (PRISMA-ScR): checklist and explanation. Ann Intern Med 2018;169(7):467-73.

13. National Heart, Lung, and Blood Institute (NHLBI). Study quality assessment tools. Washington DC: NIH; 2019.

14. Sterne JAC, Savović J, Page MJ, Page RG, Blencowe NS, Boutron I, Cates CJ, Cheng H-Y, Corbett MS, Eldridge SM, Hernán MA, Hopewell S, Hróbjartsson A, Junqueira DR, Jüni P, Kirkham JJ, Lasserson T, Li T, McAleenan A, Reeves BC, Shepperd S, Shrier I, Stewart LA, Tilling K, White IR, Whiting PF, Higgins JPT. RoB 2: a revised tool for assessing risk of bias in randomised trials. BM7 2019; 366:14898.

15. Soremekun OA, Biddinger PD, White BA, et al. Operational and financial impact of physician screening in the ED. Am 7 Emerg Med 2012;30(4):532-9.

16. Han JH, France DJ, Levin SR, Jones ID, Storrow AB, Aronsky D. The effect of physician triage on emergency department length of stay. The Fournal of Emergency Medicine. 2010;39(2):227-233.

115. Abdulwahid MA, Booth A, Kuczawski M, Mason SM. The impact of senior doctor assessment at triage on emergency department performance measures: systematic review and meta-analysis of comparative studies. Emergency Medicine Fournal 2016; 33(7): 504-513.

116. Abualenain J, Rasooly I, Levett P, Alabdranalnabi T, Pines $\mathrm{J}$. The impact of interventions to reduce length of stay in the emergency department: a systematic review. Acad Emerg Med 2013;20(5 Suppl 1):S160.

117. AJ Carter, AH Chonichov. A systematic review of the impact of nurse practitioners on cost, quality of care, satisfaction and wait times in the emergency department. C7EM 2007;9(4).

118. Rowe BH, Guo X, Villa-Roel C, Schull M, Holroyd B, Bullard M, Vandermeer B, Ospina M, Innes G. The role of triage liaison physicians on mitigating overcrowding in emergency departments: a systematic review. Academic Emergency Medicine 2011;18(2): 111120.

119. Bullard MJ, Villa-Roel C, Guo X, et al. The role of a rapid assessment zone/pod on reducing overcrowding in emergency departments: a systematic review. Emerg Med 7 2012;29(5):372-8.

120. Cabilan CJ, Boyde M. A systematic review of the impact of nurse-initiated medications in the emergency department. Australas Emerg Nurs 7 2017;20(2):53-62.

121. Ospina MB, Kelly K, Klassen TP, Rowe BH. Publication bias of randomized controlled trials in emergency medicine. Acad Emerg Med 2006;13(1):102-8. 